\title{
Construction of College English Wisdom Classroom under the Internet
}

\author{
Yinya Huang \\ Zhejiang Yuexiu University, Shaoxing, China \\ Email:20131050@zyufl.edu.cn
}

How to cite this paper: Huang, Y.Y. (2021) Construction of College English Wisdom Classroom under the Internet. Open Access Library Journal, 8: e7545.

https://doi.org/10.4236/oalib.1107545

Received: May 18, 2021

Accepted: July 6, 2021

Published: July 9, 2021

Copyright $\odot 2021$ by author(s) and Open Access Library Inc.

This work is licensed under the Creative Commons Attribution International License (CC BY 4.0).

http://creativecommons.org/licenses/by/4.0/

\section{(c) (i) Open Access}

\begin{abstract}
At present, in the process of accelerating the overall development of China's society, the educational cause has embarked on the road of the latest reform. More and more effective education ideas have been put forward, which has optimized the effect of students' knowledge learning and laid a foundation for students' subsequent growth and development. This paper focuses on the actual situation of English classroom teaching activities in universities and colleges. It discusses the construction strategies of college English wisdom class under the background of the Internet. It will be able to really use high-tech technology and to find a powerful development path for the smooth development and implementation of the internal English education in universities and colleges. It will make great contribution to the future healthy growth of our university students.
\end{abstract}

\section{Subject Areas}

Language Education

\section{Keywords}

Internet, College English, Wisdom Classroom

\section{1. 引言}

高校内部教学工作的主要任务是为社会培养一批专门的、高技术的人才。 对人才培养而言, 正确定位人才培养理念, 就需要有针对性地开展有效的教 育活动, 优化课堂教学效果。在这样的背景下, 网络可以实现资源共享, 也 可以使校园教育工作整体水平得到良好的提升。本文针对大学英语这门学科 的基本情况, 分析了网络环境下智慧课堂的具体实施方法, 从而可以运用新 的教育理念以及有效的教学方法, 优化英语课堂, 不断深入地进行知识点探 
索, 提高学习成绩。

\section{2. 互联网下大学英语智慧课堂的构建现状}

在大学英语课堂教学的发展和实施过程中应注意以下几个方面: 大多数 教师没有根据教学目标和学生的智力学习需要对教学内容进行补充和加工。 如果仅仅是把教材的内容强行渗透到课堂中, 那么教材的使用效果不佳, 整 个课堂也难以利用多媒体发挥其优势, 激发学生的学习兴趣, 这导致学生注 意力不集中, 学习成绩不断下降。例如: 在讲解 “controversial, discrimination” 这些单词时, 不少教师在教学过程中使用多媒体软件, 把英文单词和中文翻 译展示出来, 并给出单词的造句内容。实际上这种内容与教材内容相似, 缺 乏创新意义, 不能充分利用多媒体技术的优势。这样的教材往往不利于学生, 影响学生的学习状态。

\section{3. 互联网下大学英语智慧课堂构建的意义}

在互联网这一时代的背景下, 学生们的生活状态, 还有学习的习惯也呈 现出了一系列的变化。很大一部分人通过互联网接入的智能手机, 能够真正 的在网上实现订单、地图的查阅和在线的学习 [1]。所以想要真正的保证大学 校园的学生能够更加深刻地对相关的知识有所理解, 就需要加深其知识学习 的效果, 通过运用、体验、反思等一系列的过程, 保证学生能够对每一个环 节的内容有着更加深刻的印象。这样才能够促使大学校园内部英语课堂教学 工作符合学生学习的习惯, 提高学生实际的学习效果。

以往的大学英语课堂上整体的教学模式开展过于单一, 缺乏多样性, 这 也不利于学生学习兴趣的培养。这样的情况导致整个课堂在知识传授的环境 下, 学生的思维会受到限制, 日积月累学生的思维空间也会变得狭窄, 甚至 受到禁锢[2]。所以在智慧课堂构建的过程之中, 能够最大程度的改善传统的 教学工作所具有的弊端, 也能够利用线上线下结合的方法, 真正地发挥出互 联网教育所具有的优势, 让学生形成一个良好的学习生态圈。这也能够使学 生积极主动地参加到课堂之中, 提高其学习的效果和质量。同时, 借助互联 网的工具, 能够进一步地提高大学英语课堂教学的活力, 丰富学生知识学习 的手段, 让学生对英语的电影短片进行欣赏, 对英文歌曲进行聆听, 这些都 能够让学生感受到英语知识学习的乐趣。这也是互联网背景下, 大学校园内 部英语智慧课堂构建所具有的意义。

\section{4. 互联网下大学英语智慧课堂的构建策略}

（一）利用多媒体技术创造教学情境，激发学生学习兴趣

在大学英语课堂教学活动的开发和实施中，教师还需要充分利用多媒体 技术, 利用多媒体中的视频、动画和图像等方法, 将声音和图像真正结合起 来, 同时能够实现情景的融合, 为学生提供最佳的语言学习环境。这种课堂 教学工作随着时代的发展, 可以提高学生的课堂体验, 激发学生的积极主动 性, 与学生建立良好的语言表达能力。 
例如: 在讲解 “dread to” 这个短语时, 在教材中就提到了 “dread to lose”、 “dread losing” , 教师需要基于场景的教学材料, 真正联系到学生的真实生 活, 利用多媒体技术的编辑功能, 为学生创造一个害怕的对话场景。让所有 的情景、展示的英语相关知识真正成为学生的静态书本知识。将动态的多媒 体学习转化为技术知识, 让学生在进行学习时更加直观, 提高学生的学习兴 趣提高课堂效率, 进一步提高课堂质量 [3]。

（二）多媒体教学以生为本，体现学生主体性

在大学英语课堂多媒体教学设计中, 教师应充分发挥以人为本。由于这 些课程改革要求教育工作必须以学生为中心, 并围绕学生开展一系列教学活 动 [4]。还需要根据学生的学习需求, 合理设计多媒体教学模式, 在首选教学 活动的支持下, 组织学生参与教学活动的动机和主动性, 突出学生的主体地 位。

在开展大学英语教学活动中, 教师应充分考虑学生的兴趣、知识和学习 的需要, 将多媒体教学与纸质教材教学相结合, 充分发挥两者的优势 [5]。为 了合理设计大学英语教学活动的发展模式。例如: 在讲解 “universe” 的过程 中, 老师看到黑板上写的单词后, 要通过多媒体课件展示出宇宙的相关情景。 宇宙浩瀚的视频图像, 加上特效音乐, 在每一个行星上都会显示一个字母,

“universe”这个词会完整地呈现给学生。然后各个行星发出声音: “My name is earth.” 通过这种方式，学生可以有效地被多媒体视频动画所吸引，同时提 高他们获取知识的欲望, 从而提高学习效果, 调动课堂教学气氛。

(三) 在多媒体教学中注重互动教学, 培养学生自主学习能力

大学英语课堂在教学过程和教学活动的实施过程中, 要使教学达到最大 化, 教师需要将交互式多媒体的概念融入到教学过程中, 充分发挥多媒体教 学的优势, 进行有效的课堂交互设计, 提供更多独立思考和探索学习空间。

在教学过程中, 教师利用多媒体材料制作教材, 并与学生分享教材内容, 使学生能够进行学前实践, 使学生能够自主编写教材, 这样学生就可以清楚 地注意到所出现的问题, 教师也可以在课堂上得到反馈。例如: 在《Discovering your niche holiday》中, 当教师根据课程内容, 预先录制好影像媒体, 以视频 的形式, 让校园的学生可以观察到教师所使用的多媒体视频内容, 从而保证 学生更直观地了解到循环的过程, 然后自主学习英语单词和句子, 记下你不 懂的知识点和疑问, 并在课堂上提出这些问题, 老师统一回答。这种方法不 仅能使课堂教学取得最佳效果, 也能够激发学生学习的积极性, 发挥出智慧 课堂的优势。

(四) 微课为英语学习提供资料

微课是指运用信息技术按照认知规律, 呈现碎片化学习内容, 过程及扩 展素材的结构化数字资源。微型课堂的教学方法主要是教师通过设计课堂教 学模式来完成录像, 帮助学生更好地掌握知识内容。因此, 在设计阶段, 除 了需要对教学中最重要和最困难的方面保持密切的了解外, 教师还需要回到 课堂教学的步骤, 逐步展开适当地介绍和复习课堂上需要学习的内容。

在课堂教学中, 教师需要对教学现场进行直接分析, 加深学生对课堂知 识内容的印象, 使不同层次的学生能够自动找到学习课堂知识的切入点 [6]。 
微型课程的导向性有助于教师整个课程的发展, 也有助于实现课堂设计的初 步构想。在课堂教学的过程中, 结合使用微课视频的模式, 能够保证学生随 时随地对视频内容进行观看, 回顾课堂上的知识点, 以便于更好的提高课堂 教学的效果。教师通过课堂向学生传授知识内容, 从而保证学生在课堂知识 的展示过程中做好充分的准备。这充分发挥了微课教学的优势, 使课堂设计 更具前瞻性, 也提高了教育的整体质量, 使学生在教师和微课的帮助下积累 更多的英语知识, 提高学习效果和水平。

(五) 为课堂语言交流提供载体

对于许多大学生来说, 英语学习是比较枯燥的, 而小班化的交际特点可 以增加师生之间以及学生之间的交流。因此, 教师还需要运用实证的方法, 对学生进行反复的学习和知识练习为了解决学生在英语知识学习中所遇到的 一系列问题, 为学生的知识学习和成长提供条件。

例如, 在教学中, 教师应尽可能地向学生传达英语学科的特点, 使他们 更多地了解单词的语法和拼写规则。教师在微课的视频录制过程中要提出问 题, 为学生创造良好的自主学习环境, 使学生在自主学习基本概念的同时解 决教师提出的问题[7]。一旦不能解决问题, 他会在第二天的课上做标记和报 告。在课堂教学过程中, 教师应以这些问题为切入点, 引导学生对所涉及的 知识内容进行深入的分析、交流和研究。这样的课堂环境能有效地促进学生 之间的交流, 也能使学生在一个相对一致的环境中, 解决学习中存在的问题, 避免枯燥的课堂现象, 从而提高了学生的课堂参与提高英语知识学习效果。

(六) 结合互联网背景培养学生的学习兴趣

对大学生来说, 对知识学习过程的兴趣是他们最好的老师, 能够通过有 效地激发学生的学习兴趣。由此可见, 兴趣的调动直接关系到学生在课堂学 习中的主动性和积极性。在阅读教学过程中, 教师还应有效地培养学生学习 阅读知识的兴趣, 保证学生的主动性和积极性得到充分调动使学生在课堂上 有一定的活动水平, 从而提高学习效果, 促进学生的进步。

教师可以利用互联网技术，通过视频、背景图片等多种方式结合起来阅 读学生的英语文本, 有选择地与各种元素结合 [8]。将声音、视频、动画等效 果融入课堂从而有效地吸引学生的注意力, 为学生的流动性, 参与英语阅读 训练的过程。例如: 在 “Can you play the guitar?” 的讲解中, 当这部分知识 与互联网技术相结合时, 老师可以制作一个简短、简洁的视频, 展示 guitar 演奏的情况、演奏技巧、guitar 演奏的场景等, 通过观看真实场景, 学生能够 即时了解课文中所描述的中心思想以及相关内容, 并能迅速被这些内容所吸 引, 产生强烈的阅读兴趣。通过这种方式, 学习者可以积极参与知识的学习 过程, 摆脱被动学习的原始状态, 真正提高以主动学习意志为指导的阅读能 力。

(七) 结合互联网背景营造良好的教学情境

大学阶段的英语课堂作业, 以往的阅读教学采用传统的方式, 课堂导入 一般都是以教师为榜样, 通过教师的口语, 向学生传达独特而枯燥的内容, 导入方式很枯燥有效地吸引学生的注意力。因此, 在这种教学情境下, 学生 也容易出现紧张和焦虑的现象, 往往会感到疲劳, 导致教师的新课导入效果 
不佳。

根据这种情况, 希望结合使用互联网进行阅读练习的学生可以输入与文 本相关的视频内容, 使用视频方法输入知识点。文章中所描述的动植物可以 在课堂上创造一种声音和图像相结合, 然后再与适当的背景音乐相结合的阅 读情境, 创造课堂气氛, 激发学生的学习积极性。例如: 在讲解 “Trouble in modern times” 这篇文章的时候, 文章中叙述的重点是 trouble。在课堂导入 过程中, 教师可以利用互联网技术作为主要媒介, 展示一些 trouble 片段, 展 示各种场景等。这样, 就可以为学生以后阅读文章创造一个良好的环境, 并 为学生对文章内容产生足够的兴趣, 使他们处于愉快的心理状态。将阅读知 识融入英语学习过程, 提高学生的阅读能力。

(八) 结合互联网背景丰富、拓展教学素材

对于大学生来说, 短期的课堂时间是有限的知识内容, 他们可以学习。 因为大多数一堂课课程持续 40 到 45 分钟, 老师只能用这段时间来解释知识。 然而, 如果学生失去注意力或注意力不集中等, 这可能会导致上课时间的显 著减少。教师还必须学会利用网络技术来活跃课堂气氛, 让学生轻松愉快地 学习英语, 从而增强他们的自信心 [9]。

例如: 在讲解 《Where did you go on vacation?》的部分知识时, 教师可 以把网络技术作为课堂素材的基础, 通过它包括多媒体技术, 利用我的想象 力将城市景观、人文景观、自然景观他们需要英语有相应的注释, 从而使学 生在幻想英语知识的过程中, 增加词汇的积累, 以及复习旧知识和传达新内 容的能力活跃课堂气氛提高教学效率。

（九）灵活运用恰当手段, 创设良好学习氛围

良好的英语学习环境是激发学生英语学习兴趣、调动学生学习积极性的 重要条件, 也是培养学生英语学习环境的必要途径 [10]。因此, 在课堂教学过 程中, 教师还需要有针对性地激发学生的学习兴趣, 让学生参与各种活动, 提高自己的学习水平。因此, 在教学阶段, 教师可以利用情境创设的模式, 为学生提供最佳的知识学习环境。

例如: 在学生的英语活动中, 教师可以利用现代化的手段和相应的技术, 用图像、视频、音频等多种方式进行展示, 使学生在一个更加生动的环境中, 提高自己的英语学习知识, 它还可以使英语信息, 有效地刺激感官 [11] [12]。 因为, 在很多学生学习的过程中, 良好的氛围是知识学习阶段非常重要的一 部分内容, 教师可以用图像来表现, 相关的保证这些图像内容与现实生活相 结合, 学生在学习过程中可以产生情感, 从而也或多或少地让学生在成长的 过程中每个人都有自己的东西。在这种情况下, 老师需要引导学生真正学会 解决和接受他们的成长问题, 并鼓励学生与自己的情况联系起来, 大胆地谈 论他们所经历的成长故事 [13] [14]。通过这种方式, 创设具有真实情感的课堂 教学情境, 可以激发学生对所学知识内容的讨论兴趣, 并在学生之间的交流 过程中产生良好的语境。为了最大限度地提高英语课堂教学效果。

\section{5. 结论}

综上所述, 在最近课程改革的大背景下, 互联网逐渐成为教育部门最重 
要的支持工具 [15]。基于本文的内容, 分析了大学英语课堂教学活动中, 网络 技术是一种具体的实施策略和方法, 其主要目的是真正运用新的课堂教学方 式, 提高教学质量, 使学生在知识的基础上, 取得自己的主要成绩。课堂教 学改革就是要超越知识教育, 从知识走向智慧, 引导学生和教师爱智慧, 追 求智慧。智慧课堂让学生在英语教学中感受过程, 获得规律, 真正发展智慧。

\section{Conflicts of Interest}

The authors declare no conflicts of interest.

\section{References}

[1] 赵倩倩. 移动互联视域下的大学英语智慧教学模式研究 [J]. 海外英语, 2021(6): 157-158.

[2] 李亚红. 基于智慧课堂的英语师范生教学创新能力培养 [J]. 教育观察, 2021, 10(5): 80-82.

[3] 李丰苪. “互联网+智慧课堂”背景下打造信息化商务英语口译课一一以云班课为 例 [J]. 湖北开放职业学院学报, 2021, 34(2): 176-177.

[4] 张婧, 朱成棋. 基于教育大数据的大学英语智慧课堂学习模型研究 [J]. 海外英语, 2020(21): 145-146+152.

[5] 董彩华. 基于 “互联网+”下的大学英语读写智慧课堂建设 [J]. 数字通信世界, 2020(11): 206-207.

[6] 何晓粀. 智慧课堂在民族院校大学英语教学中的应用研究 [J]. 英语广场, 2020(30): 61-63.

[7] 程绍鸾. 浅析英语智慧课堂教学模式对体育专业学生语言学习能力的培养[J]. 产 业与科技论坛, 2020, 19(20): 127-128.

[8] 同银萍. 基于 “互联网 + ”的大学英语智慧课堂的构建与评价 $[J]$. 微型电脑应用, 2020, 36(9): 74-76.

[9] 姜辰娟. “互联网+教育”背景下英语教学范式变革展望[J]. 英语广场, 2020(19): 66-69.

[10] 程慧. “互联网 + ”背景下应用型本科英语口语自主学习能力培养研究 [J]. 文化创 新比较研究, 2020, 4(19): 164-166.

[11] 安富海. 促进深度学习的课堂教学策略研究 [J]. 课程, 教材, 教法, 2014, 34(11): 57-62.

[12] 彭红超. 智慧课堂环境中的深度学习设计研究 [D]: [博士学位论文]. 上海: 华东 师范大学, 2019: 5-6.

[13] Biggs, J. (1979) Individual Differences in Study Processes and the Quality of Learning Outcomes. Higher Education, 8, 381-394. https://doi.org/10.1007/BF01680526

[14] 孙曙辉, 刘邦奇. 智慧课堂 [M]. 北京: 北京师范大学出版社, 2016: 34-35.

[15] 祝智庭. 智慧教育新发展: 从翻转课堂到智慧课堂及智慧学习空间[J]. 国内高等 教育教学研究动态, 2016(19): 11 . 


\section{Appendix (Abstract and Keywords in Chinese)}

\section{互联网下大学英语智慧课堂构建}

摘要: 目前, 在我国社会整体发展速度不断加快的过程中, 教育事业走 上了最新改革的道路。越来越多有效教育理念的提出, 优化了学生知识学习 的效果, 也为学生的后续成长和发展奠定了基础。本文是在大学院校内部, 以英语课堂教学活动的开展实际情况为核心, 重点了解到互联网这一背景下, 大学英语智慧课堂的构建策略。希望能够真正的借助高科技技术, 为大学院 校内部英语教育工作的顺利开展和实施找到有力的发展路径, 从而实现学生 的长足发展和进步, 为我国大学院校学生的未来健康成长做出巨大的贡献。

关键词: 互联网, 大学英语, 智慧课堂 